\title{
IN PERSUIT OF ALTERNATIVE INGREDIENTS TO CEMENT CONCRETE CONSTRUCTION
}

\author{
K. Rajendra Prabhu ${ }^{1}$, Subhash C Yaragal $^{2}$ and Katta Venkataramana ${ }^{3}$ \\ ${ }^{1}$ Research Scholar, ${ }^{2 \& 3}$ Professors, Dept. of Civil Engineering, NIT, Karnataka, India, subhashyaragal@yahoo.com
}

\begin{abstract}
Due to rapid demand and growth in infrastructure, the natural resources are fast depleting. The production of cement and aggregates consume energy which are responsible for increase in concentration of carbon dioxide in atmosphere. On the other hand huge amount of wastes are generated in various fields which are not being utilized other than for landfilling, incineration and a very few reused having a recycle value. Some wastes are biodegradable while others are toxic or harmful to environment. Hence there appears to be an urgent need to search for alternative materials, which can replace existing ingredients partially or fully, thereby reducing energy consumption and reduced $\mathrm{CO}_{2}$ emission. This paper discusses some options which appear to be promising in this direction.
\end{abstract}

Index Terms: Eco-Friendly Concrete, Sustainability, Substitutes for Binders, Substitutes for Aggregates

\section{INTRODUCTION}

Concrete is a man-made material, prepared by using locally available materials. Basically it consists of aggregates (fine and coarse) bonded together by binding material. The binder is formed from a mixture of hydraulic cement and water. An ordinary concrete consists mainly Ordinary Portland Cement (OPC), river sand, crushed stone aggregate and water. The advantage of this material is it can be cast into any shape, size and at any place, and its property can be tailored to suite the desired needs. It is economical, fire resistant, anti-corrosive and termite-proof when compared to wood and steel.

OPC is manufactured from naturally occurring materials like limestone and clay. The aggregates which are inert are classified as Fine Aggregate (FA) and Coarse Aggregate (CA), FA is usually dredged from river while $\mathrm{CA}$ is obtained by crushing rocks. Water used can be from any source which is found fit for drinking.

This paper addresses issues and options related to environmental concerns, durability and sustainability, alternative materials to binders and aggregates.

\section{ENVIRONMENTAL CONCERN}

To pursue a holistic approach for sustainable industrial development, one must start practicing industrial ecology. Simply stated, the practice of industrial ecology implies that waste products of one industry are recycled as substitutes for virgin raw materials of other industries, thereby reducing the environmental impact of both.

Coal is used as a fuel in manufacturing process of cement. $\mathrm{CO} 2$ released during calcination of limestone and also while burning coal, totaling an equal amount by weight of cement clinker.

The two best strategies to obtain a major reduction in carbon dioxide emission associated with cement production are to lower the clinker factor (clinker per ton of cement) of the final product as much as possible by maximizing the proportion of mineral additions in cement, and to increase the use of blended cements in general construction.

The cement industry is already recycling hazardous organic wastes as fuel for clinker burning, thus recovering the energy value and conserving virgin fuel resources. Reportedly, portland-cement clinker is also a safe sink for a variety of toxic elements present in these hazardous wastes. Therefore, portland-cement concrete is able to safely incorporate millions of tons of fly ash, slag, and other industrial by-products that contain toxic metals.

It was found that fly ash, slag, silica fume and rice husk ashes, which are industrial waste products, were possessing cementitious properties due to presence of siliceous materials, which required minor treatment before put to use. They are also called as latent hydraulic binders, supplementary cementitious materials (SCM), pozzolans or cement replacement materials (CRM). They are blended with OPC with respective percentages (20 to 70 percent by weight of total cementitious material) based on their effectiveness of pozzolanic activity. They are called as mineral admixtures when incorporated in concrete. All types of SCM's when mixed with cement $(\mathrm{OPC})$ react with the hydration products of OPC mainly $\mathrm{Ca}(\mathrm{OH}) 2$ in presence of water and at normal curing temperature to form CSH gel. (CSH: Calcium Silicate Hydrate, which is the main cement hydration product) 
Pozzolans are found to be reactive (hydrate) only when their particle size is less than $45 \mu \mathrm{m}$. Although particle size characteristics, composition of glass, and the glass content are primary factors determining the reactivity of fly ash and slags, it may be noted that the reactivity of the glass itself varies with the thermal history of the material. The glass, chilled from a higher temperature and at a faster rate, will have a more disordered structure and will therefore be more reactive.

Pozzolans when blended with cement are found to perform better than OPC. The $\mathrm{Ca}(\mathrm{OH}) 2$ which easily dissolves and leaches out when concrete comes into contact with water, thereby allowing ingress of harmful chemicals and gases into concrete from where the deterioration starts. In fact, the pozzolans consumes $\mathrm{Ca}(\mathrm{OH}) 2$ and makes concrete dense and less impermeable while cement alone releases $\mathrm{Ca}(\mathrm{OH}) 2$. The engineering benefits likely to be derived from the use of mineral admixtures in concrete include improved resistance to thermal cracking due to low heat of hydration, enhancement of ultimate strength and impermeability due to pore refinement, strong interfacial transition zone, and very high durability to sulfate attack and alkali-aggregate expansion.

Recently, a total replacement of OPC by inorganic polymer is found out, and named as geopolymer, which uses SCM and alkalies as binder.

There is a scarcity of river sand and also some of the states have banned quarrying sand from rivers for ecological reasons. Hence manufacture of crushed stone sand is gaining momentum. Recently Crushed rock fines which are a byproduct of stone crushing unit (also sometimes called as Quarry Dust) has found an entry into construction field, i. e., by blending with sand. It is free from deleterious materials and salt content but has more fines content. Ash from various sources are also finding potential in partially replacing sand.

Energy is consumed while quarrying and crushing of coarse aggregates. Lots of industrial and domestic solid wastes like ceramics, glass, construction and demolition wastes (CDW) and slag which are inorganic in nature and coconut shell chips, rubber from tyres, polymers, plastics, and sewage sludge which are organic in nature can replace natural aggregates partially or fully.

Most waste waters and undrinkable natural waters can be substituted for municipal water for mixing concrete unless proven harmful by testing.

Similarly various substitutes for fibres have been identified, like recycled plastics, natural fibres from banana tree, sugarcane bagasse, bamboo, etc.

\section{CONCRETE DURABILITY AND SUSTAINABILITY}

The practice of industrial ecology, as described earlier, provides only a short term solution towards sustainable development in concrete industry. In the long run, sustainable development will happen only if one makes dramatic improvements in our resource productivity.

Large savings in materials can result in the future if one begins to make products that would last much longer. For example, the resource productivity of concrete industry can leap by a factor of five if most of the structures built today would endure for 250 years instead of the conventional 50 .

Today's humanity's eco footprint is $40 \%$ larger than what the planet can generate. That means the earth takes 1-1/2 years to grow, what human beings use in 1 year, clearly this is unsustainable.

\subsection{ALTERNATE MATERIALS TO BINDERS}

\subsection{Alkaline Cements as an Alternative in the Transition}

The first use of alkalis as a component of cementitious materials dates back to 1930, when Kuhl studied the setting behaviour of mixtures of slag ground to a powder and a $\mathrm{KOH}$ solution. Since that time many studies have been conducted on the role that alkalis may play in potential cementitious systems. One early milestone was reached in 1940, when Purdon conducted the first extensive laboratory study on clinkerless cements consisting of slag and $\mathrm{NaOH}$. In 1967 Glukhovsky made a significant breakthrough in the understanding and development of binders from low calcium or calcium-free alumino silicate (clay) and alkaline metal solutions. He called these binders "soil cements" and the respective concretes "soil silicates". Glukhovsky classified binders into two groups, depending on the composition of the starting materials: alkaline binding systems Me2O-Al2O3$\mathrm{SiO} 2-\mathrm{H} 2 \mathrm{O}$ and "alkali-alkaline-earth" binding systems $\mathrm{Me} 2 \mathrm{O}-\mathrm{MO}-\mathrm{Al} 2 \mathrm{O} 3-\mathrm{SiO} 2-\mathrm{H} 2 \mathrm{O}$ (where $\mathrm{Me}=\mathrm{Na}, \mathrm{K}, \ldots$ and $\mathrm{M}=\mathrm{Ca}, \mathrm{Mg}, \ldots)$.

This set off extensive research on and developments in alkali activated cement and concrete, although both the intensity and direction of this type of research were haphazard and subject to contemporary scientific and technological needs.

Initially, most alkali activation effort focused on the materials classified by Glukhovsky in group 2 (alkali-alkaline-earth binding systems $\mathrm{Me} 2 \mathrm{O}-\mathrm{MO}-\mathrm{Al} 2 \mathrm{O} 3-\mathrm{SiO} 2-\mathrm{H} 2 \mathrm{O}$ ); Scandinavian F-cements and alkali-activated blended cements are good examples of research in this regard. 
The last ten years, however, have seen exponential growth in research related to Glukhovsky's first group of materials (alkaline binding systems: $\mathrm{Me} 2 \mathrm{O}-\mathrm{Al} 2 \mathrm{O} 3-\mathrm{SiO} 2-\mathrm{H} 2 \mathrm{O}$ ). And although in 1982 Davidovits produced binders by mixing alkalis with a burnt mix of kaolinite, limestone and dolomite (calling the binders geopolymers while also generating a number of trademarks such as Pyrament, Geopolycem and Geopolymite), these cements have only recently began to acquire true technological significance.

At the same time the gradually growing knowledge base on alkali- activated cements and concretes has cast light not only on their benefits in terms of low energy costs and environmental impact, but also their good mechanical performance and long durability.

\section{Classification and characteristics of alkali-activated cements}

Alkali-activated cements usually consist of two components: a cementitious component and alkaline activators. Caustic alkalis or alkaline salts are normally used as alkaline activators in alkali activated cements and concretes. A variety of industrial by-products and waste as well as a number of alumino-silicate raw materials has been used as the cementitious components in alkali-activated cements and concretes. These materials include granulated blast furnace slag, granulated phosphorus slag, steel slag, coal fly ash, volcanic glass, zeolite, metakaolin, silica fume and nonferrous slag.

Using the composition of the cementitious component(s) as a criterion, alkali-activated cements can be classified into five categories:

(1) Alkali-activated slag-based cements

(2) Alkali-activated pozzolan cements

(3) Alkali-activated lime-pozzolan/slag cements

(4) Alkali-activated calcium aluminate blended cements

(5) Alkali-activated portland blended cements (hybrid cements)

\section{Alkaline activation as a model for transition to the design of new alternative cements. Future research}

One significant example of the scientific and technical gap in alkali activation procedures is the lack of a systematic and orderly study of the mechanisms governing the effect of the known alkali activators (sodium and potassium hydroxides, silicates, carbonates and sulfates) on silico aluminous materials. The relationship between "reaction mechanisms, the chemistry of alkaline activating solutions and end product properties" needs to be explored, along with the decisive effect of calcium (with enormous technological implications) on such mechanisms.

While alkaline silicate solutions have likewise been widely used in alkaline activation, essential aspects of the reactive process are still poorly understood, such as the effect of the various chemical species present in the solution on reaction kinetics or the composition of the end product. Finally, working with solid activators instead of alkaline solutions would afford an enormous technological advantage, for the former would emulate one of the most estimable properties of portland cement: its conversion from a dehydrated solid state into an effective binder by mere mixing with water. In pursuit of such activators, some authors have proposed using cementitious formulas (with silico aluminous materials) that contain sodium and/or potassium carbonates or even sodium and/or potassium sulfates.

Work is needed on hybrids with a low portland clinker content and high proportion of alumino silicates, especially on their behaviour in alkaline environments. Setting, rheology, mechanical strength development and durability in this type of hybrids must also be studied.

\subsection{ALTERNATIVE MATERIALS TO}

\section{AGGREGATES}

\subsection{Crushed Stone Sand and Quarry Dust}

Crushed Stone Sand (CSS) and Quarry Dust (QD) are finding place in replacing natural sand since huge demand on one side and depletion of natural source on the other side. The Indian Standards (IS 383-1970) recognize the use of CSS in making concrete. The Clause 2.1 identifies three types of Fine Aggregates, namely Natural Sand, Crushed Stone Sand and Crushed Gravel Sand.

CSS is referred by various other names such as Manufactured Sand, Crushed Rock Sand, while QD as Crushed Rock Fines (CRF). The grading requirements as per IS 383-1970, the allowable percentage of materials passing through 150 microns are higher (20\%) for CSS compared to natural river sand. CSS, due to its angular shape, rough texture and sharp edges compared to rounded shape and smooth surface of natural sand, reduce workability of concrete which in turn consume plasticizer to compensate it. As the river sand gets finer near the mouth of river, it possesses finer particles and hence a coarser CSS can be blended to it.

QD is a waste product generated during crushing of stones in aggregate manufacturing industry, containing majority of particle size less than or equal to that specified in Zone IV. Even though CSS and QD are Fine Aggregates (based on the particle size), it possesses most of the properties of Coarse Aggregates.

QD is used as fine aggregate either on its own or blended with river sand (RS). In cases where the river sand is coarse with very low percentage of particles below 600 microns, it affects the cohesiveness of the concrete, and hence can be blended with QD. As the river sand is coarser along its origin, it can be 
blended with QD to supplement its deficiency of finer particles.

The pump-ability of concrete also relies on the percentage of particles passing 300 microns, and more the fines content better is the pumping. To design cohesive mixes, whether it is transported manually or by pump, it would be extremely difficult to do so using only natural sand. Therefore, in these circumstances, the ideal way to improve the properties of Fine Aggregates is to blend Natural River Sand with QD accordingly to meet the Zoning Criteria.

The strength of concrete in addition to water cement ratio depends on the degree of compaction. Concrete which is not cohesive will not be able to achieve full compaction. Therefore, the use of QD in fact helps to produce dense cohesive concrete, thereby improving the strength.

Both CSS and QD are free from clay and silt content, which improves bonding of cement paste with aggregates and hence no loss of strength. They are also free from chloride content, which does not initiate corrosion of reinforcement and hence make RCC structures more durable. It is free from deleterious materials like wooden pieces, shells, mica, and pebbles. It is economical and available wherever there is production of crushed aggregates and one can get consistent quality throughout the year. As they are engineered materials, the quality can be assured and there is no wastage due to sieving which in turn saves labour, time and energy. Since it is a byproduct of aggregate industry, no extra energy consumed in production, and hence a greener product.

\subsection{Construction and Demolition Waste / Recycled}

\section{Aggregates}

Large quantities of construction and demolition wastes are obtained either during construction as debris and when the structure is demolished. They are usually in the form of brick bats, mortars, aggregates, concrete, glass, ceramic tiles, metals and plastics. They are to be mechanically sorted according to size and quality and later crushed to desired size as per needs.

A disadvantage of demolished concrete waste is its low density, and as a result its high porosity. Hence, more water is required to ensure full saturation of RA during concrete mixing and it may also require more intensive compaction. The inferior quality of DC can lower the quality of their RA and RAC. It is important to measure the characteristics of DC to provide a pre-requisite consideration for their RA and RAC applications. This can save time and cost for the production of inferior quality RA and ensure that high quality RA is produced for higher-grade concrete applications. RAC design requirements can also be developed at the initial concrete demolition stage.
Recycled demolished concrete (DC) as recycled aggregate (RA) and recycled aggregate concrete (RAC) is generally suitable for most construction applications. (Low-grade applications, including sub-base and roadwork).

\subsection{Waste Polymers}

A polymer is a large molecule (macromolecule) composed of repeating structural units. Most commonly, the continuously linked backbone of a polymer used for the preparation of plastics consists mainly of carbon atoms.

A substantial growth in the consumption of plastic is observed all over the world in recent years, which has led to huge quantities of plastic-related waste. Recycling of plastic waste to produce new materials like concrete or mortar appears as one of the best solution for disposing of plastic waste, due to its economic and ecological advantages. Several works have been performed or are under way to evaluate the properties of cement-composites containing various types of plastic waste as aggregate, filler or fibre.

Plastic, one of the most significant innovations of 20th century, is a ubiquitous material. A substantial growth in the consumption of plastic is observed all over the world in recent years, which also increases the production of plastic-related waste. The plastic waste is now a serious environmental threat to modern civilization. Plastic is composed of several toxic chemicals, and therefore plastic pollutes soil, air and water. Since plastic is a non-biodegradable material, land-filling using plastic would mean preserving the harmful material forever.

The majority of the plastics contain toxic organic and inorganic chemical constituents such as lead, cadmium, chromium, mercury, bromine, tin, antimony, bisphenol A, and chloro-ethane monomer, and therefore the leaching of these toxic constituents from plastic waste-based concrete is another key aspect to be addressed when evaluating the possible degree of pollution.

Recycling plastics is a possible option. As plastic is an organic hydrocarbon-based material, its high calorific value can be used for incineration or in other high temperature processes. But, burning of plastics releases a variety of poisonous chemicals into the air, including dioxins, one of the most toxic substances. Plastic waste can also be used to produce new plastic based products after processing. However it is not an economical process as the recycled plastic degrades in quality and necessitates new plastic to make the original product.

Although these alternatives are feasible except for land-filling, recycling of plastic waste to produce new materials, such as cement composites, appears as one of the best solution for disposing of plastic waste, due to its economic and ecological advantages. A vast work has already been done on the use of 
plastic waste such as polyethylene terephthalate (PET) bottle, poly vinyl chloride (PVC) pipe, high density polyethylene (HDPE), thermosetting plastics, expanded polystyrene foam (EPS), glass reinforced plastic (GRP), polycarbonate (PC), polyurethane foam (PUR), polypropylene fibre as an aggregate, a filler or a fibre in the preparation of concrete.

The introduction of plastic aggregates as partial replacement to natural aggregates will reduce the strengths whereas the fibres arrest the plastic cracks and also improve the toughness. However, the amount of plastic addition can be increased substantially if particles are further processed to improve the bond with matrix and stress transfer capacity of the particles.

\subsection{Waste Tyre Rubber}

Polymeric wastes namely tyre rubber and PET represents a major environmental problem of increasing relevance. An estimated 1000 million tyres reach the end of their useful lives every year. At present enormous quantities of tyres are already stockpiled (whole tyre) or landfilled (shredded tyre), 3000 million inside EU and 1000 million in the US. By the year 2030 the number of tyres from motor vehicles is expect to reach 1200 million representing almost 5000 million tyres to be discarded in a regular basis.

Tyre landfilling is responsible for a serious ecological threat. Mainly waste tyres disposal areas contribute to the reduction of biodiversity also the tyres hold toxic and soluble components. Secondly although waste tyres are difficult to ignite this risk is always present. Once tyres start to burn down due to accidental cause's high temperature take place and toxic fumes are generated besides the high temperature causes tyres to melt, thus producing an oil that will contaminate soil and water. In Wales a tyre dump with 10 million tyres has been burning continuously for 9 years. The implementation of the Landfill Directive 1999/31/ EC and the End of Life Vehicle Directive 2000/53/EC banned the landfill disposal of waste tyres creating the driving force behind the recycling of these wastes. Still millions of tyres are just being buried all over the world. Tyre rubber wastes are already used for paving purposes; however, it can only recycle a part of these wastes. Another alternative are artificial reef formation but some investigation have already questioned the validity of this option. Tyre waste can also be used in cement kilns for energetic purposes and to produce carbon black by tyre pyrolysis, a thermal decomposition of these wastes in the absence of oxygen in order to produce by-products that have low economic viability. Some research has already been conducted on the use of waste tyre as aggregate replacement in concrete showing that a concrete with enhanced toughness and sound insulation properties can be achieved. Rubber aggregates are obtained from waste tyres using two different technologies: mechanical grinding at ambient temperature or cryogenic grinding at a temperature below the glass transition temperature. The first method generates chipped rubber to replace coarse aggregates. As for the second method it usually produce crumb rubber to replace fine aggregates. Since the cement market demand is expected to have a twofold increase this means that concrete volume is expect to increase in a similar pattern representing an excellent way to reuse wastes like tyre rubber.

Recent research shows that there are two specific areas where the specification of plain rubberized concrete (PRC) and selfcompacting rubberized concrete (SCRC), as opposed to conventional mix designs, can offer significant advantages in the plastic and hardened state over the properties of conventional concrete: (i) Firstly, where rubber aggregates create low unit weight mixes with a higher degree of air entrainment that can be easily pumped at higher flow rates, and provide improved levels of thermal and/or acoustic insulation. Additional applications could include roadway central reservations that offer combined protection and traffic noise reduction, improved thermal and acoustic insulation for small machinery housing structures, and also improved thermal insulation for flooring in buildings. (ii) Secondly, rubberized concrete can provide significantly improved dynamic loading behaviour and impact/vibration absorption characteristics. Future research into applications that take advantage of these properties could focus on damped flooring for mounting machinery, highway and rail crash barriers, personal shelters/bunkers for defence and counter terrorism measures, rocket launching platforms and sea wall defences.

The current weaknesses and limitations of rubberized concrete are well documented, i.e. reduced strength and stiffness and limited to non-structural or modest loading applications. It appears that the key to better understanding and overcoming this behaviour is in the interfacial transition zone (ITZ). SCRC could provide an attractive solution for shrinkage cracking and strain failure as a result of incorporating the waste rubber particles which leads to more deformability under pre-failure loads, as well as increased toughness, impact resistance and ductility compared with standard SCC.

\subsection{Agricultural Wastes}

The majority of wastes generated from agricultural sources are sugarcane bagasse, straw and husk of wheat and paddy, vegetable wastes, food products, oil production, shells of coconuts and groundnuts, jute fibre, saw dust, cotton stalk. They can be used in concrete as a fibres, aggregates or fillers. The ash obtained by burning any one of the above is found to have a potential in concrete making as a SCM.

The applications of agricultural wastes as aggregate or cement replacement material in concrete have engineering potential and economic advantage. Each type of agricultural waste has physical and chemical properties, which are suitable in proper application in concrete. In low-cost lightweight structures, solid agricultural waste as coarse aggregate together with cement matrix can meet design specifications. Agricultural wastes can also be used in non-load bearing concrete where 
compressive strength is not important. Agricultural fibres can be used in concrete to produce particle boards, roofing sheets, and partition panels. Rice husk ash and palm-oil-fuel-ash can be used as cement replacement materials. Pre-treatment is necessary for oil palm shell (OPS) aggregate before using in concrete because it contains dust and oil coating. Various pretreatment processes are (i) partial oxidation of organic aggregate, (ii) waterproofing, (iii) neutralisation with alkali or precipitation of tannates, or sulphate treatment, (iv) mixing with lime or calcium chloride for better performance of concrete as an accelerator, (v) micro organism treatment of aggregate by boiled water with ferrous sulphate, and (vi) removing oil coating with detergent and water.

\subsection{Waste Ash}

The ash is a waste product as a result of burning the solid fuel or solid wastes collected at the bottom of furnace or from the chimneys.

The municipal solid waste (MSW) is usually disposed by land filling or incinerated (It is a waste treatment process that involves the combustion of organic substances contained in waste materials. Incineration of waste materials converts the waste into ash, flue gas, and heat).

Refuse-derived fuel (RDF) and the mass-burning processes are the two most widely used processes of incinerating MSW. The refuse-derived fuel process consists of first separating metals and glass from the MSW, and then it is shredded and incinerated, and the generated heat is recovered to produce electricity. The mass-burning process consists of burning the MSW as it is received in the plant without waste separation or shredding. The by-product of the incineration process is ash. Depending upon the nature of the incineration plant, ash is typically $1-30 \%$ by wet weight and $5-15 \%$ by volume of the wet MSW. Incineration of MSW produces two types of the ashes; bottom ash and fly ash. Bottom ash residues are large and heavy particles which are removed from the bed of the incinerator whereas fly ash residues are very fine particles entrained in exhaust gases. Bottom ash constitutes $75-80 \%$ of the total combined ash stream. Majority (approximately 90\%) of the bottom ash consists of grate ash, which is the ash fraction that remains on the stoker or grate at the completion of the combustion cycle. It is similar in appearance to porous, greyish, silty sand with gravel, and contains small amounts of unburnt organic material and chunks of metal. The grate ash stream consists primarily of glass, ceramics, ferrous and nonferrous metals, and minerals.

\section{CONCLUSIONS}

One of the challenges for the construction industry in the future will be to reuse waste materials with new technologies, produced at reasonable cost and with the lowest possible environmental impact
The infrastructure shall be designed using sustainable principles (lower environmental impact, judicious use of resources i.e., energy conservation and use of by products and high performance product) in order to reduce its demand on the environment and existing infrastructure.

A radical change in the future of binders for construction is only possible if all the stakeholders involved in this broad area of work (scientific community, industry, and users) are fully committed to the endeavor.

The manufacture of CSS can be tailored and QD can be blended with sand in improving cohesiveness and pump ability of concrete making a denser concrete. They do not contain deleterious materials as those found in natural sand.

Aggregates from construction demolition, plastics, waste tyre rubber, agricultural wastes and MSW bottom ash requires an effort of pretreatment either physically or chemically before they are to be used for works like low grade and light weight concrete.

Use of alternative ingredients in construction material and simultaneously solves the environmental problem of reducing waste.

\section{REFERENCES}

[1] A. M. Neville, "Properties of Concrete", Low prince 4th edition 2006, Pearson Education.

[2] Caijun Shi, A. Fernández Jiménez, Angel Palomo (2011) "New cements for the 21st century: The pursuit of an alternative to portland cement". Journal of Cement and Concrete Research, Vol 41, pp 750-763

[3] Dora Foti, (2011), "Preliminary analysis of concrete reinforced with waste bottles PET fibers", Construction and Building Materials 30 (2011) pp 1906-1915

[4] F. Pacheco-Torgal, Yining Ding, Said Jalali, (2012), "Properties and durability of concrete containing polymeric wastes (tyre rubber and polyethylene terephthalate bottles): An overview", Construction and Building Materials 30 (2012) pp $714-724$

[5] H.B. Basri , M.A. Mannan, M.F.M. Zain, (1999), "Concrete using waste oil palm shells as aggregate", Cement and Concrete Research 29 (1999) pp 619-622

[6] IS:383-1970, "Specification for coarse and fine aggregates from natural sources for concrete"

[7] K.B. Najim, M.R. Hall (2010) "A review of the fresh/hardened properties and applications for plain- (PRC) and self-compacting rubberised concrete (SCRC)", Construction and Building Materials 24 pp 2043-2051

[8] K. Gunasekaran, P.S Kumar and M. Lakshmipathy (2011), "Study on Properties of Coconut Shell as an Aggregate for Concrete", ICI Journal July - September 2011, pp 27-33

[9] M.A. Mannan, C. Ganapathy, (2004) "Concrete from an agricultural waste-oil palm shell (OPS)", Building and Environment 39 (2004) pp 441 - 448 
[10] Mohd Syahrul Hisyam bin Mohd Sani, Ahmad Rasidi Osman, Fadhluhartini bt Muftah, (2011),“Comparison Study of Bottom Ash Aggregate and Washed Bottom Ash Aggregate in Concrete: Physical Aspect", 2011 IEEE Symposium on Business, Engineering and Industrial Applications (ISBEIA), Langkawi, Malaysia pp 178-18

[11] Nabajyoti Saikia, Jorge de Brito, (2012), "Use of plastic waste as aggregate in cement mortar and concrete preparation: A review", Construction and Building Materials 34 (2012) pp $385-401$

[12] P. Kumar Mehta and Paulo J. M. Monteiro, "Concrete: Microstructure, Properties, and Materials", Third Edition, McGraw-Hill

[13] Rafat Siddique, (2010), "Use of municipal solid waste ash in concrete", Resources, Conservation and Recycling 55 (2010) pp 83-91

[14] T.R. Naik, S.S. Singh, C.O. Huber and B.S. Brodersen, (1996) "Use of post-consumer waste plastics in cement-based composites" Cement and Concrete Research, Vol. 26, No. 10, pp. 1489-1492.

[15] Urs Müller, Katrin Rübner, (2006) “The microstructure of concrete made with municipal waste incinerator bottom ash as an aggregate component", Federal Institute for Materials Research and Testing (BAM), Division VII.1-Building Materials, Unter den Eichen 87, D-12205 Berlin, Germany, Cement and Concrete Research 36 (2006) pp 1434-1443

[16] Vivian W.Y. Tama, K. Wang, C.M. Tam (2008) "Assessing relationships among properties of demolished concrete, recycled aggregate and recycled aggregate concrete using regression analysis", Journal of Hazardous Materials 152 pp 703-714

[17] Liz Butler, "Estimating the environmental impacts of concrete" CEES 2313, Water Quality Fundamentals, School of Civil engineering and Environmental Science, University of Oklahoma, Norman, OK downloaded from http://lcs.syr.edu/centers/SustainableEngineering/modules/1028_Butler.pdf, 5th March 2013

\section{BIOGRAPHIES:}

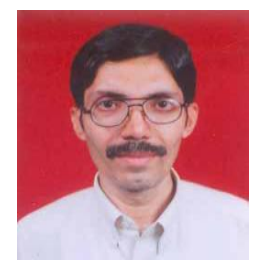

Rajendra Prabhu obtained his B.E (Civil) and M. Tech (Structural Engg.) from MIT, Manipal. He worked in the areas of consultancy, teaching and ready mix concrete industry. Currently he is pursuing his doctoral degree in the area of concrete technology in NITK, Surathkal.

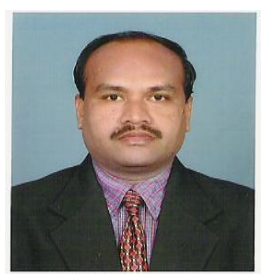

Subhash C Yaragal graduated from NITK Surathkal and obtained his post graduation and doctoral degrees from the Indian Institute of Science, Bangalore. Currently he is serving as Professor and Associate Dean (Academic). His areas of interest include concrete technology, concrete performance, pipeline engineering and building aerodynamics and wind tunnel testing.

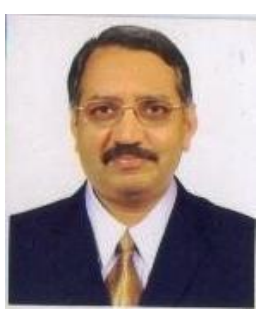

Katta Venkataramana graduated from NIE Mysore, did his Master's degree from Kagoshima University, Japan. He obtained his doctoral degree from University of Kyoto, Japan. He is serving as Professor in the department of Civil Engineering, NITK, Surathkal from 2002. Currently he is also discharging his duties as Head of the Department. His areas of research interests include Earthquake engineering and Earthquake resistant design, concrete technology, etc. 